\title{
Is the uranium isotope proxy a reliable indicator of ferruginous conditions?
}

\author{
JACOB T PEREZ ${ }^{1}$, GEOFFREY GILLEAUDEAU ${ }^{2}$, \\ ELIZABETH SWANNER, PHD ${ }^{3}$ AND STEPHEN J \\ ROMANIELLO ${ }^{1}$ \\ ${ }^{1}$ University of Tennessee \\ ${ }^{2}$ George Mason University \\ ${ }^{3}$ Iowa State University \\ Presenting Author:.jperez15@vols.utk.edu
}

Uranium (U) isotope variations $\left({ }^{238} \mathrm{U} /{ }^{235} \mathrm{U}\right)$ recorded in the rock record have seen widespread use as a paleoredox proxy for understanding variations in ancient ocean chemistry. The basis of this proxy is the large positive isotope fractionation which accompanies the reduction of soluble U(VI) to insoluble U(IV). This isotopic fractionation factor has been predicted theoretically via $a b$ initio calculations and subsequently confirmed by microbial $\mathrm{U}(\mathrm{VI})$-reduction experiments and observations of $\mathrm{U}$ isotope fractionation in natural sulfidic marine basins, such as the Black Sea. However, in abiotic U(VI) reduction experiments, the situation is less clear. Experiments using Fe(II) solutions and minerals have shown variable degrees of isotope fractionation, and even isotopic fractionation in the opposite direction [1]. Furthermore, experiments conducted using variable concentrations of dissolved $\mathrm{Ca}^{2+}$ have shown that the magnitude of $U$ isotopic fractionation can be systematically controlled via changes in solution chemistry [2]. These results demonstrate the need to better understand the reaction mechanisms responsible for $U$ reduction in ancient environments - particularly in the presence of $\mathrm{Fe}(\mathrm{II})$ - and how these processes impact the overall degree of $\mathrm{U}$ isotopic composition that occurs during reduction.

In detail, there are many factors which impact the dominant pathway(s) of U(VI) reduction in natural environments. These include biotic vs. abiotic reduction; one-electron vs. two-electron donors (e.g. Fe(II) vs. sulfide); the presence or absence of U(V) as a significant reaction intermediate; variations in reaction kinetics and $\mathrm{U}(\mathrm{VI})$ aqueous speciation; homogenous vs. heterogeneous (surface-absorbed) reduction pathways; and the ultimate chemical form of the U(IV) solid product.

Here we propose a systematic set of experiments to deconvolute the role of the various factors above in controlling the isotopic fractionation of $\mathrm{U}$ during reduction with $\mathrm{Fe}(\mathrm{II})$. These experiments include systematic exploration of homogeneous and heterogeneous reductants and variations in $\mathrm{U}$ aqueous speciation and reaction kinetics. By carefully controlling the reaction conditions, intermediates, and products, these experiments will help to discern the dominant patterns of $U$ isotope fractionation which may have characterized ancient ferruginous oceans.

[1] Stylo et al. (2015) PNAS 112(18): 5619-5624 [2] Brown et al. (2018) PNAS 115(35): 8688-8693 